\title{
Ground-Based Solar UV Radiation Monitoring Technique Using Photocell
}

\author{
Paribesh Koirala*, Raj K. Tripathee, Nitesh Pandey \\ Pulchowk Campus, Institute of Engineering, Tribhuvan University, Nepal
}

\begin{abstract}
This paper presents Solar UV radiation monitoring technique using a photo voltaic cell. The data obtained by such technique can be used to calculate the UV index and measure risk of UV exposure. UV irradiance at the surface is affected by the solar elevation, total ozone, clouds, aerosol, surface albedo etc. This paper presents results from the designed instrument to evaluate the UV index. The data obtained from such method will have benefit in installation, maintenance, data transfer and operational cost. This paper highlights the development and initial validation of standard UV data along with the portable embedded device for personalized UV monitoring which is based on a novel programming technique, photo Voltaic Cell as UV sensor, and a microcontroller PIC16F877A. This portable personalized UV monitoring device just provides the tentative UVI as it does not take the depth of ozone layer into account. Rough estimation of UVI can be obtained with such embedded system.
\end{abstract}

\section{Introduction}

Ultraviolet (UV) radiation is electromagnetic radiation with a wavelength shorter than that of visible light, but longer than high energetic radiation like X-rays, lying in the range $10 \mathrm{~nm}$ to $400 \mathrm{~nm}$, with energies from $3 \mathrm{eV}$ to $124 \mathrm{eV}$. It is so named because the spectrum consists of electromagnetic waves with frequencies higher than those that humans identify as the color violet. UV light is found in sunlight and is emitted by electric arcs and specialized lights such as black lights. It can cause chemical reactions, and causes many substances to glow or fluoresce. [Navid Amini, Computer Science Department, University of California, Los Angeles, CA 90095, USA A wireless embedded device for personalized Ultraviolet monitoring (cs.ucla.edu)]

The Global Solar UV index (UVI) determines the level of solar UV radiation on the Earth's surface (Maddodi and Setaluri, 2008, HKO (Hong Kong Observatory), 2008). The foremost intention of the UVI is to provide easy concept to the public about the skin damaging UV radiation.

The value of the index ranges from zero and upward while index of ' 0 ' corresponds to zero UV irradiation. The higher the index value, the greater is the potential for damage to the skin and eye, and thus lesser is the time for harm to occur. The UV index is an open-ended linear scale as:

$$
U V I=k \int_{250}^{400} E . s d \lambda
$$

where ' $\mathbf{E}$ ' is the solar spectral irradiance expressed in $\mathrm{W} / \mathrm{m}^{2} / \mathrm{nm}$ ) at wavelength $\lambda$ and ' $d \lambda$ ' is the wavelength interval used in the summation. ' $\mathbf{s}$ ' is the erythema reference action spectrum, and ' $\mathbf{k}$ ' is a constant equal to $40 \mathrm{~m}^{2} / \mathrm{W}$ (NOAA-EPA Brewer Network, NEUBrew UVindex.pdf). World 
Health Organization as categorized the level of UV in different extent and is summarized in Table 1.

Table 1: UV Index category

\begin{tabular}{|l|l|}
\hline UVI & Extent \\
\hline $0-2$ & Low \\
\hline $3-5$ & Moderate \\
\hline $6-7$ & High \\
\hline $8-10$ & Very High \\
\hline 11,12 and + & Extreme \\
\hline
\end{tabular}

UVI can be determined with measurement or from model calculations. Two types of measurement techniques are used to calculate the UVI. For the ground based measurement, Spectroradiometers that use the above formula and Broadband radiometers that are calibrated and programmed in order to give UVI directly are used.

The personalized UV monitoring device used in this study is an approach to monitor the UVI for the particular time to provide the indication of strength at any place with an economic way. Solar Radiation and Aerosols in Himalayan Region (SAHR) is monitoring the UV radiation in Nepal installing NILU-UV multi channel radiometer that measures UV irradiances at five channels with center wavelengths at $305,312,320,340$ and $380 \mathrm{~nm}$. The channel bandwidths are approximately $10 \mathrm{~nm}$ at full width half maximum (FWHM). In addition, the sixth channel measures photosynthetic active radiation (PAR) in the wavelength region 400-700 nm. The optical part of the instrument consists of a Teflon diffuser, silicium detectors and high quality bandpass filters. Implementation of the personalized UV monitoring device is cheap and can be installed in every location of concern. Being a cheap approach to monitor UVI, personalized UV monitoring device can be installed in more cities. Acquiring the data of the intermediate regions would help to develop UVI map of the city or the whole country itself.

Major flaw in forecasting of the UVI of certain large area by the weather stations is due to the difference in the effects of ozone, atmospheric pollutants, and aerosols. This alters UV intensity and it is not taken into account during calculation. This is prominent especially in urban areas. While on the other hand, the forecast does not take into account variable surface reflection (e.g., sand, water, concrete or snow), which can substantially increase individual's exposure at the mountains, water banks or on snowy-slopes.

\section{Methodology}

The NILU-UV radiometer was used to calibrate the personalized UV measurement system developed. The dose rate obtained from the NILU-UV multichannel radiometer is used to calculate the UVI. Thus calculated UVI is the standard UVI for further testing using this instrument.

The hardware and software structure of the proposed personalized UV device are explained in the proceeding subsections. 


\section{System Design:}

Figure 1 shows the schematic diagram of the personalized UV monitoring device. The UV sensor is the Photo Voltaic (PV) cell. The analog voltage from the PV panel is fed into the microcontroller (PIC16F877A) where analog to digital conversion is done by the analog to digital converter (ADC). The analog voltage fed from the input-output $(\mathrm{I} / \mathrm{O})$ of the microcontroller is converted into 10 bits digital signal and the microcontroller calculates the voltage. This calculated digital voltage is stored into the memory of the microcontroller. The system is designed in such a way that the microcontroller takes the voltage from the PV cells at an interval of five minutes and stores the digitized value of the voltage in the memory. The interface between the microcontroller and the computer is done through serial to USB which extract the data stored in the memory of the microcontroller. The application tiny-boot-loader was used to communicate between the microcontroller and the computer (serial to USB communication).

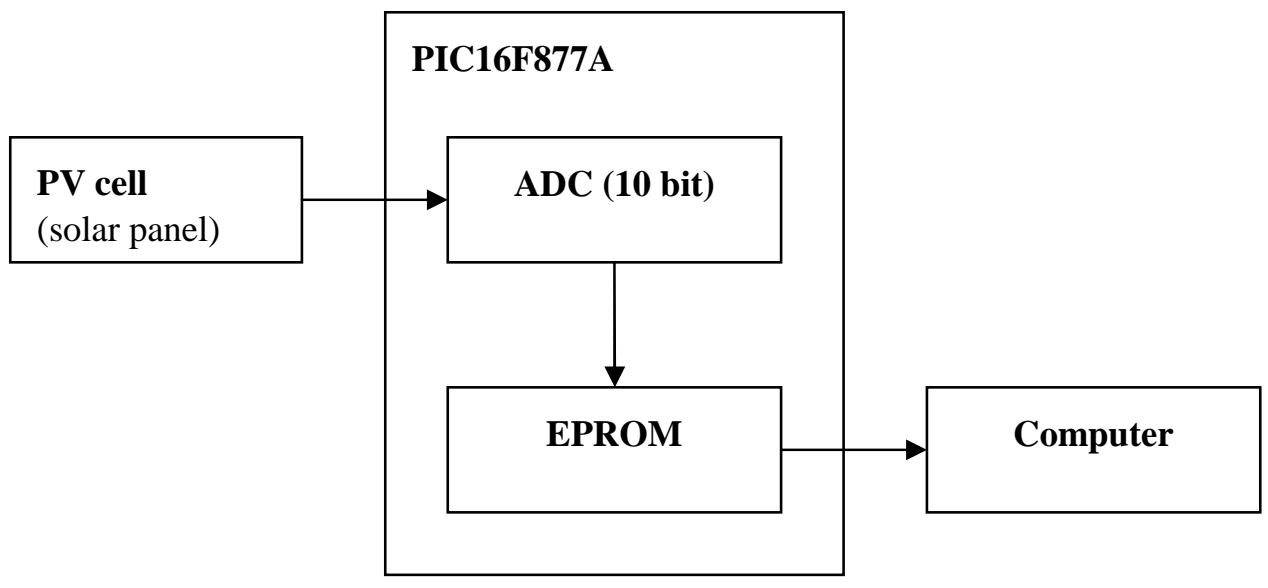

Figure 1

\section{Calibration and Testing:}

The output of the personalized UV monitoring system was the voltage taken every five minutes. This personalized system was placed in the premises of the Pulchowk Campus, Institute of Engineering (IOE) where the NILU-UV is installed. The regression line is drawn. Comparing the output voltage from the microcontroller with the standard UVI to get the conversion formula an empirical relation was derived as shown below.

\section{Calculated UVI $=b_{1}+b_{2} *$ voltage}

where $b_{1}$ and $b_{2}$ are the coefficients of the regression line.

Hence the UVI is calculated using above formula. 
Regression Statistics

\begin{tabular}{|l|l|}
\hline Multiple R & 0.96 \\
\hline R Square & 0.91 \\
\hline Adjusted R Square & 0.91 \\
\hline Standard Error & 0.33 \\
\hline Observations & 38.00 \\
\hline
\end{tabular}

\begin{tabular}{|l|l|l|}
\hline & Coefficients & Standard Error \\
\hline Intercept & 0.05 & 0.13 \\
\hline X Variable 1 & 4.09 & 0.21 \\
\hline
\end{tabular}

Output UVI $=b_{1}+b_{2}{ }^{*}$ voltage

Then the regression coefficients are used to further calculation of UV. The test was carried for two days with different weather conditions and the results are tabulated in appendix.

The personalized UV monitoring device was left for testing after its calibration. The error percentage was calculated to determine the efficiency of the personalized UV monitoring device. The test was carried out on different weather conditions, one on the sunny day and the other on the cloudy day. As stated earlier the result gives the indication of the level of UVI since the ozone concentration during calibration and real time measurement will not be same.

\section{RESULTS}

The relation between the voltage provided by the sensor (PV cell) and NILU-UV during calibration is given in table 2 to obtain regression line. The statistics of the data is also shown in the same table. The table below shows the relation between the output voltage with the standard UVI i.e. UVI from the NILU-UV. The table is used to draw the regression line between the voltage and the UVI from the NILU-UV. UVI at a place is calculated every five minutes using the output voltage and the regression coefficients. 
Scatter Diagram and Residual Plot:

Day 1:
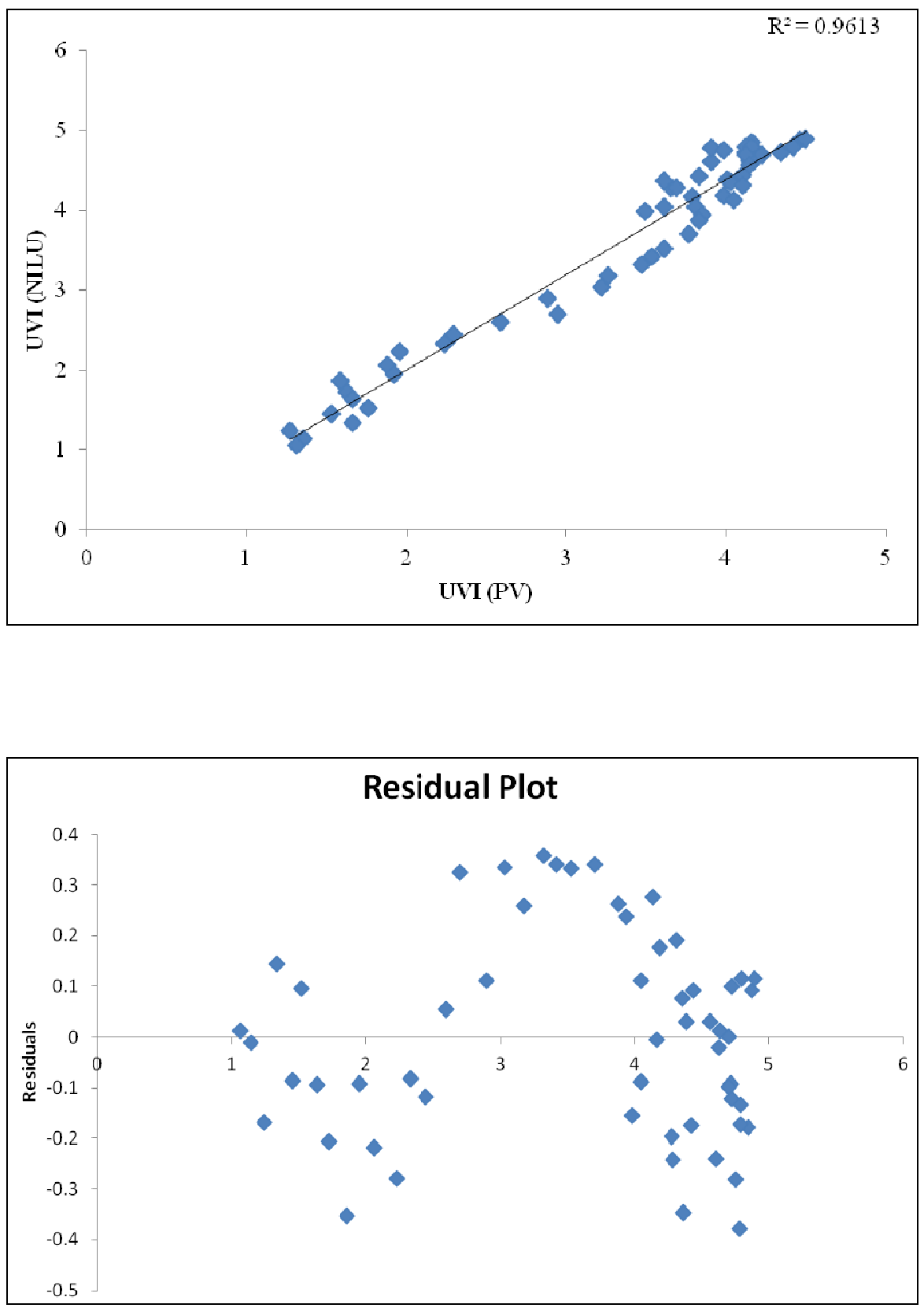
Day 2:
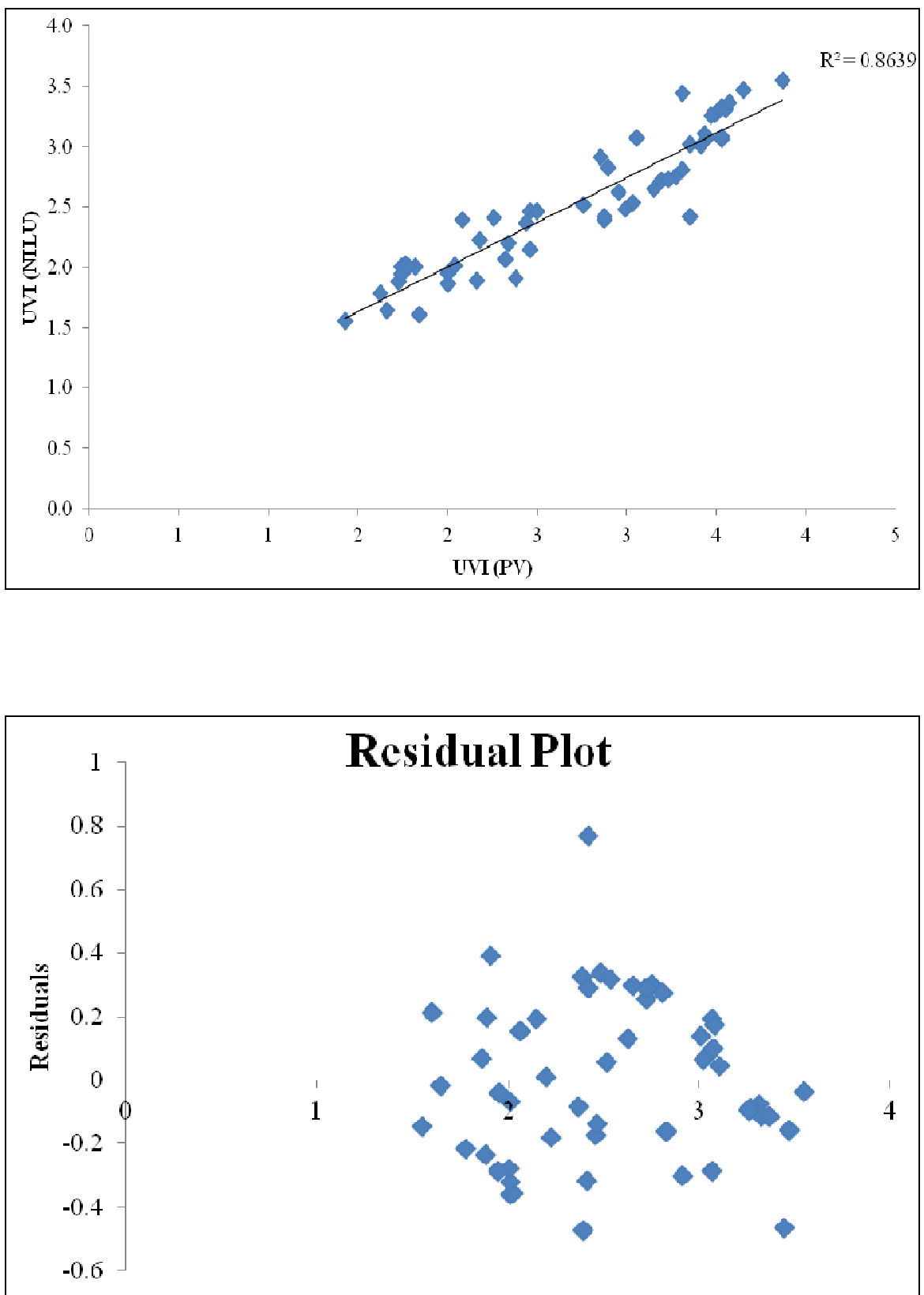

The scatter diagram depicts how much the variable fits to the regressed line. If the residual square is higher, the variables fit to the regressed line. The square of residual of the first test is higher in comparision with the second thus the output of first test is highly correlated with the line of regression. 
Whereas the residual plot shows the variation of the variable (UVI-PV) with the average value of UVI. This shows how much the UVI of PV deviates from the average value of UVI. The values of day 1 are less scattered than the day 2 .

\section{Conclusion}

In this paper we adopt Photo Voltaic Cell as UV sensor to implement a real-time and personalized UV monitoring. The personalized UV monitoring device explained in this stuey can be put on the location of interest. It is not obtrusive and is portable in nature. Since the system is small, economical, it proved to be very feasible.

As the device was implemented in the premises of Pulchowk Campus, IOE, the effect of the ozone layer was not considered in the calculation of UVI. The depth of ozone layer was assumed to be same in the test site throughout the measurement period.

The PV based UVI monitoring device is unable to measure the UVB present in the solar radiation as it got absorbed by the plastic cover present in the PV cell. On the other hand the analog voltage from the PV cell is due to UVA along with some part of visible rays near UVA, which gives the tentative UVI of the site. Thus the UVI calculated is the approximation. Some part of visible rays near UVA provides the sensor the energy that is changed into analog voltage which is roughly near to the energy of UVB missed out by the sensor. Hence the personalized UV monitoring device roughly estimates the UVI at a place.

Since, the personalized UV monitoring device is economical, portable and easy to implement, installation in numerous locations is easy once if a look up table is made for different ozone level. Hence the UVI map of certain location of interest can be generated with the result. This would help to validate the Satellite UV data.

\section{Acknowledgement}

Solar Radiation and Aerosol in Himalaya Region (SAHR), Institute of Engineering is acknowledged for encouraging and providing necessary data for the calibration purpose. Binod $\mathrm{K}$. Bhattarai, SAHR is thankful for encouragement and constructive criticism. Special thanks also go to Mr. Niranjan Sharma, SAHR and Mr. Sandeep Manandhar, Pulchowk Campus for his support for this work.

\section{REFERENCES}

[1] NILU, The NILU-UV Irradiance Meter User's Manual Version 2.1, 2008.

[2] NRPA, Intercomparison and harmonization of UV Index measurements from multiband filter radiometers, http://www.nrpa.no, as of 14 April 2011.

[3] WMO, GAW Report No. 179 Intercomparison of Global UV Index from Multiband Filter Radiometers: Harmonization of global UVI and spectral irradiance (http://www.wmo.int/pages/prog/arep/index_en.html), as of 14 April 2011. 
[4] Difey B. L., Sources and measurement of ultraviolet radiation, http://www.academicpress.com, as of 26 April 2011.

[5] PIC16F87XA Data Sheet

[6] http://www.freepatentsonline.com/6459087.html

[7] http://users.ntua.gr/mmakro/UVsource-measurem.pdf

[8] SAHR IOE, http://www.ioe.edu.np/sahr

[9] Operating manual, Solar Light Company, 501 UV- Biometer, http://www.solar.com, 2008.

[10] Maddodi N., Setaluri V., Role of UV in Cutaneous Melanoma, Journal of Photochemistry and Photobiology, 84, No. 2, pp. 528-536, 2008.

[11] HKO, Hong Kong Observatory, UV index forecast, http://www.hko.gov.hk.

[12] Navid Amini, Computer Science Department, University of California, Los Angeles, CA 90095, USA A wireless embedded device for personalized Ultraviolet monitoring (cs.ucla.edu), 2008.

\section{APPENDIX}

Table 2: Calculation of UVI (PV) comparing with UVI (NILU-UV)

\begin{tabular}{|c|c|c|c|c|c|}
\hline $\begin{array}{c}\text { Output } \\
(\mathrm{HEX})\end{array}$ & Output (DEC) & $\begin{array}{c}\text { voltage } \\
(\mathrm{mV})\end{array}$ & Calculated UVI & $\begin{array}{c}\text { Standard } \\
\text { (dose rate) }\end{array}$ & standard UVI \\
\hline $\mathrm{cf}$ & 207 & 0.99 & 4.12 & 0.11 & 4.29 \\
\hline $\mathrm{d} 4$ & 212 & 1.02 & 4.22 & 0.11 & 4.32 \\
\hline $\mathrm{d} 2$ & 210 & 1.01 & 4.18 & 0.11 & 4.26 \\
\hline $\mathrm{d} 4$ & 212 & 1.02 & 4.22 & 0.10 & 4.15 \\
\hline $\mathrm{d} 6$ & 214 & 1.03 & 4.26 & 0.10 & 4.08 \\
\hline $\mathrm{d} 7$ & 215 & 1.03 & 4.28 & 0.10 & 3.99 \\
\hline $\mathrm{da}$ & 218 & 1.05 & 4.34 & 0.10 & 3.97 \\
\hline $\mathrm{cd}$ & 205 & 0.98 & 4.08 & 0.10 & 3.93 \\
\hline 68 & 104 & 0.50 & 2.10 & 0.07 & 2.65 \\
\hline 78 & 120 & 0.58 & 2.41 & 0.07 & 2.85 \\
\hline 68 & 104 & 0.50 & 2.10 & 0.07 & 2.79 \\
\hline 76 & 118 & 0.57 & 2.37 & 0.06 & 2.25 \\
\hline 71 & 113 & 0.54 & 2.27 & 0.07 & 2.76 \\
\hline 71 & 113 & 0.54 & 2.27 & 0.07 & 2.69 \\
\hline
\end{tabular}




\begin{tabular}{|c|c|c|c|c|c|}
\hline $6 f$ & 111 & 0.53 & 2.24 & 0.07 & 2.61 \\
\hline $6 f$ & 111 & 0.53 & 2.24 & 0.06 & 2.52 \\
\hline $6 b$ & 107 & 0.51 & 2.16 & 0.06 & 2.51 \\
\hline 67 & 103 & 0.49 & 2.08 & 0.06 & 2.37 \\
\hline 66 & 102 & 0.49 & 2.06 & 0.06 & 2.27 \\
\hline 64 & 100 & 0.48 & 2.02 & 0.06 & 2.21 \\
\hline 61 & 97 & 0.47 & 1.96 & 0.05 & 2.09 \\
\hline $5 \mathrm{f}$ & 95 & 0.46 & 1.92 & 0.05 & 1.99 \\
\hline $5 c$ & 92 & 0.44 & 1.86 & 0.05 & 1.92 \\
\hline 59 & 89 & 0.43 & 1.80 & 0.05 & 1.89 \\
\hline 53 & 83 & 0.40 & 1.69 & 0.04 & 1.76 \\
\hline $5 e$ & 94 & 0.45 & 1.90 & 0.04 & 1.67 \\
\hline $5 c$ & 92 & 0.44 & 1.86 & 0.04 & 1.66 \\
\hline $5 d$ & 93 & 0.45 & 1.88 & 0.04 & 1.54 \\
\hline 61 & 97 & 0.47 & 1.96 & 0.04 & 1.45 \\
\hline $5 f$ & 95 & 0.46 & 1.92 & 0.03 & 1.35 \\
\hline $5 e$ & 94 & 0.45 & 1.90 & 0.03 & 1.28 \\
\hline $4 d$ & 77 & 0.37 & 1.57 & 0.03 & 1.20 \\
\hline $4 a$ & 74 & 0.36 & 1.51 & 0.03 & 1.12 \\
\hline 45 & 69 & 0.33 & 1.41 & 0.03 & 1.05 \\
\hline 39 & 57 & 0.27 & 1.17 & 0.02 & 0.99 \\
\hline $2 c$ & 44 & 0.21 & 0.92 & 0.02 & 0.91 \\
\hline $2 d$ & 45 & 0.22 & 0.94 & 0.02 & 0.83 \\
\hline 21 & 33 & 0.16 & 0.70 & 0.02 & 0.77 \\
\hline
\end{tabular}

Table 3: Calculation of UVI (PV) corresponding to PV voltage, Day 1

\begin{tabular}{|c|c|c|c|c|c|c|}
\hline $\begin{array}{c}\text { Output } \\
\text { (HEX) }\end{array}$ & $\begin{array}{c}\text { Output } \\
\text { (DEC) }\end{array}$ & $\begin{array}{c}\text { Voltage } \\
(\mathrm{mV})\end{array}$ & $\begin{array}{c}\text { Calculated } \\
\text { UVI }\end{array}$ & $\begin{array}{c}\text { Standard } \\
\text { (dose rate) }\end{array}$ & $\begin{array}{c}\text { Standard } \\
\text { UVI }\end{array}$ & \% error \\
\hline af & 175 & 840 & 3.49 & 0.10 & 3.98 & 12.33 \\
\hline b5 & 181 & 868.8 & 3.61 & 0.10 & 4.05 & 10.80 \\
\hline be & 190 & 912 & 3.79 & 0.10 & 4.16 & 9.04 \\
\hline b7 & 183 & 878.4 & 3.65 & 0.11 & 4.29 & 14.88 \\
\hline b5 & 181 & 868.8 & 3.61 & 0.11 & 4.37 & 17.34 \\
\hline b9 & 185 & 888 & 3.69 & 0.11 & 4.28 & 13.80 \\
\hline c0 & 192 & 921.6 & 3.83 & 0.11 & 4.42 & 13.50 \\
\hline c4 & 196 & 940.8 & 3.91 & 0.12 & 4.60 & 15.17 \\
\hline cf & 207 & 993.6 & 4.12 & 0.12 & 4.72 & 12.75 \\
\hline
\end{tabular}




\begin{tabular}{|c|c|c|c|c|c|c|}
\hline $\mathrm{e} 0$ & 224 & 1075.2 & 4.46 & 0.12 & 4.88 & 8.62 \\
\hline e2 & 226 & 1084.8 & 4.49 & 0.12 & 4.90 & 8.19 \\
\hline $\mathrm{d} 1$ & 209 & 1003.2 & 4.16 & 0.12 & 4.84 & 14.10 \\
\hline c4 & 196 & 940.8 & 3.91 & 0.12 & 4.78 & 18.23 \\
\hline c8 & 200 & 960 & 3.98 & 0.12 & 4.75 & 16.16 \\
\hline de & 222 & 1065.6 & 4.42 & 0.12 & 4.80 & 7.92 \\
\hline $\mathrm{d} 0$ & 208 & 998.4 & 4.14 & 0.12 & 4.71 & 12.11 \\
\hline $\mathrm{cf}$ & 207 & 993.6 & 4.12 & 0.12 & 4.79 & 13.92 \\
\hline $\mathrm{d} 1$ & 209 & 1003.2 & 4.16 & 0.12 & 4.79 & 13.10 \\
\hline $\mathrm{d} 0$ & 208 & 998.4 & 4.14 & 0.12 & 4.62 & 10.44 \\
\hline $\mathrm{d} 2$ & 210 & 1008 & 4.18 & 0.12 & 4.63 & 9.75 \\
\hline $\mathrm{da}$ & 218 & 1046.4 & 4.34 & 0.12 & 4.72 & 8.10 \\
\hline $\mathrm{d} 4$ & 212 & 1017.6 & 4.22 & 0.12 & 4.70 & 10.14 \\
\hline $\mathrm{cf}$ & 207 & 993.6 & 4.12 & 0.12 & 4.70 & 12.23 \\
\hline $\mathrm{d} 0$ & 208 & 998.4 & 4.14 & 0.11 & 4.56 & 9.18 \\
\hline ce & 206 & 988.8 & 4.10 & 0.11 & 4.44 & 7.53 \\
\hline c9 & 201 & 964.8 & 4.00 & 0.11 & 4.39 & 8.76 \\
\hline $\mathrm{ca}$ & 202 & 969.6 & 4.02 & 0.11 & 4.36 & 7.64 \\
\hline ce & 206 & 988.8 & 4.10 & 0.11 & 4.31 & 4.87 \\
\hline $\mathrm{c} 8$ & 200 & 960 & 3.98 & 0.10 & 4.18 & 4.78 \\
\hline $\mathrm{cb}$ & 203 & 974.4 & 4.04 & 0.10 & 4.13 & 2.15 \\
\hline bf & 191 & 916.8 & 3.81 & 0.10 & 4.04 & 5.85 \\
\hline $\mathrm{c} 1$ & 193 & 926.4 & 3.85 & 0.10 & 3.94 & 2.28 \\
\hline $\mathrm{c} 0$ & 192 & 921.6 & 3.83 & 0.10 & 3.88 & 1.36 \\
\hline bd & 189 & 907.2 & 3.77 & 0.09 & 3.71 & -1.59 \\
\hline b5 & 181 & 868.8 & 3.61 & 0.09 & 3.52 & -2.46 \\
\hline b1 & 177 & 849.6 & 3.53 & 0.09 & 3.42 & -3.37 \\
\hline ae & 174 & 835.2 & 3.47 & 0.08 & 3.32 & -4.57 \\
\hline a3 & 163 & 782.4 & 3.26 & 0.08 & 3.18 & -2.58 \\
\hline $\mathrm{a} 1$ & 161 & 772.8 & 3.22 & 0.08 & 3.03 & -6.14 \\
\hline 90 & 144 & 691.2 & 2.88 & 0.07 & 2.89 & 0.38 \\
\hline 93 & 147 & 705.6 & 2.94 & 0.07 & 2.70 & -8.95 \\
\hline 81 & 129 & 619.2 & 2.59 & 0.06 & 2.60 & 0.34 \\
\hline 72 & 114 & 547.2 & 2.29 & 0.06 & 2.45 & 6.16 \\
\hline $6 f$ & 111 & 532.8 & 2.24 & 0.06 & 2.33 & 3.97 \\
\hline 61 & 97 & 465.6 & 1.96 & 0.06 & 2.23 & 12.08 \\
\hline $5 \mathrm{~d}$ & 93 & 446.4 & 1.88 & 0.05 & 2.06 & 8.53 \\
\hline $5 f$ & 95 & 456 & 1.92 & 0.05 & 1.95 & 1.39 \\
\hline
\end{tabular}




\begin{tabular}{|c|c|c|c|c|c|c|}
\hline $4 \mathrm{e}$ & 78 & 374.4 & 1.59 & 0.05 & 1.86 & 14.46 \\
\hline 50 & 80 & 384 & 1.63 & 0.04 & 1.72 & 5.58 \\
\hline 52 & 82 & 393.6 & 1.67 & 0.04 & 1.63 & -2.00 \\
\hline 57 & 87 & 417.6 & 1.76 & 0.04 & 1.52 & -16.18 \\
\hline $4 \mathrm{~b}$ & 75 & 360 & 1.53 & 0.04 & 1.45 & -5.35 \\
\hline 52 & 82 & 393.6 & 1.67 & 0.03 & 1.34 & -24.73 \\
\hline $3 \mathrm{e}$ & 62 & 297.6 & 1.27 & 0.03 & 1.24 & -2.86 \\
\hline 42 & 66 & 316.8 & 1.35 & 0.03 & 1.14 & -18.73 \\
\hline 40 & 64 & 307.2 & 1.31 & 0.03 & 1.06 & -23.80 \\
\hline
\end{tabular}

Table 4. Calculation of UVI (PV) corresponding to PV voltage, Day 2

\begin{tabular}{|c|c|c|c|c|c|c|}
\hline $\begin{array}{c}\text { Output } \\
\text { (HEX) }\end{array}$ & $\begin{array}{c}\text { Output } \\
\text { (DEC) }\end{array}$ & $\begin{array}{c}\text { Voltage } \\
\text { (Volts) }\end{array}$ & $\begin{array}{c}\text { Calculated } \\
\text { UVI }\end{array}$ & $\begin{array}{c}\text { Standard } \\
\text { (dose rate) }\end{array}$ & $\begin{array}{c}\text { Standard } \\
\text { UVI }\end{array}$ & \% error \\
\hline a1 & 161 & 772.8 & 3.19 & 0.07 & 2.72 & -17.29 \\
\hline a5 & 165 & 792 & 3.27 & 0.07 & 2.75 & -18.93 \\
\hline 97 & 151 & 724.8 & 2.99 & 0.06 & 2.48 & -20.53 \\
\hline ac & 172 & 825.6 & 3.41 & 0.08 & 3.01 & -13.24 \\
\hline b2 & 178 & 854.4 & 3.53 & 0.08 & 3.07 & -15.10 \\
\hline b2 & 178 & 854.4 & 3.53 & 0.08 & 3.08 & -14.53 \\
\hline b2 & 178 & 854.4 & 3.53 & 0.08 & 3.33 & -5.98 \\
\hline c3 & 195 & 936 & 3.87 & 0.09 & 3.55 & -8.90 \\
\hline a7 & 167 & 801.6 & 3.31 & 0.07 & 2.81 & -17.89 \\
\hline a3 & 163 & 782.4 & 3.23 & 0.07 & 2.73 & -18.57 \\
\hline a7 & 167 & 801.6 & 3.31 & 0.09 & 3.44 & 3.78 \\
\hline b3 & 179 & 859.2 & 3.55 & 0.08 & 3.31 & -7.08 \\
\hline a9 & 169 & 811.2 & 3.35 & 0.06 & 2.42 & -38.49 \\
\hline a9 & 169 & 811.2 & 3.35 & 0.08 & 3.02 & -10.88 \\
\hline ae & 174 & 835.2 & 3.45 & 0.08 & 3.08 & -12.13 \\
\hline b0 & 176 & 844.8 & 3.49 & 0.08 & 3.27 & -6.69 \\
\hline $9 f$ & 159 & 763.2 & 3.15 & 0.07 & 2.65 & -18.91 \\
\hline 91 & 145 & 696 & 2.87 & 0.06 & 2.39 & -20.31 \\
\hline b4 & 180 & 864 & 3.57 & 0.08 & 3.36 & -6.09 \\
\hline 99 & 153 & 734.4 & 3.03 & 0.06 & 2.53 & -19.72 \\
\hline b8 & 184 & 883.2 & 3.65 & 0.09 & 3.47 & -5.19 \\
\hline 78 & 120 & 576 & 2.38 & 0.05 & 1.91 & -24.62 \\
\hline ad & 173 & 830.4 & 3.43 & 0.08 & 3.11 & -10.35 \\
\hline
\end{tabular}




\begin{tabular}{|c|c|c|c|c|c|c|}
\hline 65 & 101 & 484.8 & 2.00 & 0.05 & 1.86 & -7.43 \\
\hline 95 & 149 & 715.2 & 2.95 & 0.07 & 2.63 & -12.54 \\
\hline 91 & 145 & 696 & 2.87 & 0.06 & 2.42 & -18.70 \\
\hline af & 175 & 840 & 3.47 & 0.08 & 3.26 & -6.36 \\
\hline 65 & 101 & 484.8 & 2.00 & 0.05 & 1.96 & -2.36 \\
\hline $9 \mathrm{a}$ & 154 & 739.2 & 3.05 & 0.08 & 3.07 & 0.50 \\
\hline 92 & 146 & 700.8 & 2.89 & 0.07 & 2.83 & -2.43 \\
\hline $7 \mathrm{c}$ & 124 & 595.2 & 2.46 & 0.05 & 2.15 & -14.50 \\
\hline $5 d$ & 93 & 446.4 & 1.84 & 0.04 & 1.60 & -14.96 \\
\hline $7 c$ & 124 & 595.2 & 2.46 & 0.06 & 2.46 & 0.14 \\
\hline 75 & 117 & 561.6 & 2.32 & 0.05 & 2.06 & -12.46 \\
\hline $6 \mathrm{~d}$ & 109 & 523.2 & 2.16 & 0.05 & 1.89 & -14.37 \\
\hline 90 & 144 & 691.2 & 2.86 & 0.07 & 2.91 & 1.91 \\
\hline 69 & 105 & 504 & 2.08 & 0.06 & 2.39 & 13.04 \\
\hline 58 & 88 & 422.4 & 1.74 & 0.05 & 2.01 & 13.18 \\
\hline 67 & 103 & 494.4 & 2.04 & 0.05 & 2.01 & -1.44 \\
\hline $5 c$ & 92 & 441.6 & 1.82 & 0.05 & 2.01 & 9.12 \\
\hline 52 & 82 & 393.6 & 1.63 & 0.04 & 1.78 & 8.74 \\
\hline $8 \mathrm{~b}$ & 139 & 667.2 & 2.76 & 0.06 & 2.52 & -9.45 \\
\hline 76 & 118 & 566.4 & 2.34 & 0.06 & 2.20 & -6.33 \\
\hline 57 & 87 & 417.6 & 1.72 & 0.05 & 1.88 & 8.40 \\
\hline 58 & 88 & 422.4 & 1.74 & 0.05 & 1.95 & 10.32 \\
\hline 72 & 114 & 547.2 & 2.26 & 0.06 & 2.42 & 6.41 \\
\hline $6 e$ & 110 & 528 & 2.18 & 0.06 & 2.23 & 2.11 \\
\hline $7 \mathrm{e}$ & 126 & 604.8 & 2.50 & 0.06 & 2.46 & -1.39 \\
\hline 54 & 84 & 403.2 & 1.67 & 0.04 & 1.65 & -1.14 \\
\hline 59 & 89 & 427.2 & 1.76 & 0.05 & 2.02 & 12.73 \\
\hline $7 b$ & 123 & 590.4 & 2.44 & 0.06 & 2.37 & -3.08 \\
\hline $5 \mathrm{a}$ & 90 & 432 & 1.78 & 0.05 & 2.01 & 11.18 \\
\hline 48 & 72 & 345.6 & 1.43 & 0.04 & 1.55 & 7.99 \\
\hline
\end{tabular}

